\title{
Design of Integrated Computer Aided Process Planning and Bill of Material in Industry 4.0 Environment
}

\author{
Rika Yunitarini*, Ernaning Widiaswanti \\ Informatics Engineering, Trunojoyo University, Indonesia.
}

\begin{abstract}
Computer aided process planning (CAPP) has been widely used as an application that is able to plan the process in manufacturing with computer technology supporting. In its implementation, the process planning stage often requires complete data/information input regarding manufacturing products that will go through several process and operations. In the assembly process for example, before planning what process and operations will be carried out on a parts, the assembler must know the specifications and product structure, so that the assembly planning process becomes directed. The purpose of this research is to perform the design of integrated computer aided process planning and bill of material as the product structure that can support the planning process activities in manufacturing area and also suitable with industry 4.0 environment whereas the rapid changes in the information and communication technologies have broken the boundaries between virtual reality and the real world.
\end{abstract}

Keywords: CAPP, Industry 4.0, Bill of Material

\section{Introduction}

In manufacture area, there are some systematic processes of detailed method that called process planning. This process planning determinate which work pieces or parts can be manufactured economically and competitively from initial stages to finished stage [1]. In practice, the CAPP application automates some or all of the manual planning processes, which is advantageous for the user because it reduces user interaction time and the resulting plan can be used more quickly by the user.

The workings of the CAPP application is to carry out an optimization process and to computerize the planning process with the help of information technology, namely software programs and optimization techniques. The impact of the CAPP application is starting to be felt by various parties, especially industry area, because it is able to produce a faster and more precise planning process, so that it is more effective and efficient. These perceived benefits have resulted in a lot of research being conducted on CAPP applications. Some of the benefits are shorter product life cycles [2]. In relation to the implementation of the CAPP application, a detailed and in-depth survey of twenty-two medium and smallscale companies using the CAPP system has been carried out. The results obtained are the achievement of process planning cost savings of $58 \%$, savings in terms of direct labor by $10 \%$, savings of $4 \%$ in terms of raw materials / materials, $12 \%$ in terms of equipment savings and $6 \%$ savings in terms of work processes [3]. In addition to the above benefits, there are also other beneficial impacts for the company, namely the creation of standardization of the planning process within a company, the CAPP interface application which is much more robust and user friendly and the increase in company productivity [4].

In the world of information technology, traditional CAPP systems are grouped into two, namely variant CAPP and generative CAPP. The way CAPP variants work is to carry out process planning for new components that are compiled by identifying and searching for existing plans in the database for the same or similar components. This variant system applies the concept that for similar/same/similar components requires process plans and assembly plans that are also similar/same. Therefore, this variant method still requires users or administrators to enter information, group component geometries, retrieve similar planning or assembly process plans in the database and then update the planning process so that a new planning process is generated for the component. In the explanation above, the variant system also applies the principle of group technology which is to group components based on the similarity of geometric shapes or functions [2]. Meanwhile, the generative CAPP does not use a standard plan for planning new components. However, based on the knowledge of the process planner to produce a process plan where the knowledge possessed uses decision logic, mathematical formulas,

\footnotetext{
*Corresponding author: rika_yunitarini@yahoo.com
} 
manufacturing rules, and geometric data to determine the processes required to convert raw materials into finished parts.

In the last few decades, there have been many product variations with various new raw materials and different technologies as well as competition among industry players [5]. Orlicky [6,7] first introduced the Bill-Of-Material as a list of the use of raw materials for an assembly or product design. BOM consists of several forms and can be used for various purposes in manufacturing or other industrial processes. The BOM is created as part of the design process and is used by the manufacturing engineer to determine which items should be purchased or produced. the grouping process based on the similarity of shape and process is better to use when compared to the grouping based on the similarity of plain components [8].

In order to achieve a competitive advantage in the industrial world, the use of information technology is very important [9]. Only companies/industry that use information technology can continue to increase their competitive advantage, so that they can continue to improve the effectiveness and efficiency of the company. Industry 4.0 is a term that refers to the process of automation and digitization of all sectors, especially the manufacturing sector [10].

The main purpose of this paper is to design an integrated website of computer aided process planning (CAPP) and bill-of-material (BOM) as data/information sources of product parts so the planning process become more effective. The remainder of this paper is organized as follows. In the next section the method for designing an integrated CAPP and BOM. Section 3 discuss about result and discussion. Finally, the conclusion is given in section 4

\section{Method}

The method used in this research is website development approach. Website is a kind of media that allows several parties to interact with each other by exchanging data or information. Furthermore, there are six stages that are usually used as stepping stones or models in carrying out website application development activities, namely: planning, analysis, design, construction, implementation, and post-implementation. Here are some of the software applications used:

a. Front-end:

1. HTML5: HTML5 allows website developers to build with the latest version of Hypertext Markup Language. This version makes it easy for developers to develop powerful websites with additional animation, music and other sophistication.

2. CSS3: Cascading Style Sheets (CSS) is a language for managing the layout of a website that is being developed.

3. jQuery: jQuery is a JavaScript library designed to simplify client side scripting. Its powerful to build websites faster.

4. JavaScript (JS): Javascript is a computer language or programming code that is used on websites to make the website more interactive and dynamic. Javascript is a type of client side programming language. The use of javascript code on a website is optional, meaning it doesn't always have to be there. However, today's modern websites and blogs almost all use javascript code even if a little.

5. Bootstrap: Bootstrap is an open-source framework used to develop responsive and mobile-friendly websites. This framework is known to be effective in facilitating the work of developers when developing the front-end design of a website to make it easier and faster.

b. Back-end:

1. PHP: PHP changes the website from static to more dynamic and changes the content and functionality of the website to be more interactive for the user's needs.

2. Laravel: Laravel is a web framework that helps you build new applications for the web, including such things as APIs or web services. Laravel sports quite a few great features like a modular packaging system along with Composer, a dedicated PHP language dependency manager. It also lets you access relational databases in different ways, and utilizes features that help in maintenance and application deployment.

3. MySql: MySQL is a software or tools to manage SQL by using queries or special languages. In this research, the design of integrated CAPP and BOM is performed by using unified modelling language (UML). UML is a standardized modelling language enabling developers to specify, visualize, construct and document artifacts of a software system.

\section{Result And Discussion}

Use case diagram is the primary form of system/software requirements for a new software program under developed. Use cases specify the expected behavior (what) and not the exact method of making it happen (how). Figure 1 below describe the functional of integrated CAPP and BOM system. The use case diagram below, consists of three actors (administrator, assembly staff, and production staff) and six use cases.

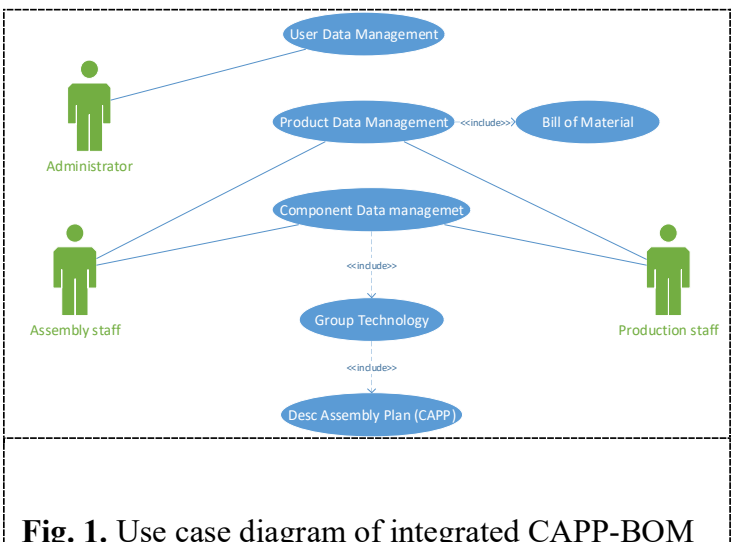

Fig. 1. Use case diagram of integrated CAPP-BOM 
A sequence diagram shows object interactions arranged in time sequence. It depict the objects and classes involved in the scenario and the sequence of message exchanged between the objects needed to carry out the functionality of the system. Figure 2 below shows the sequence diagram of integrated CAPP and BOM system.

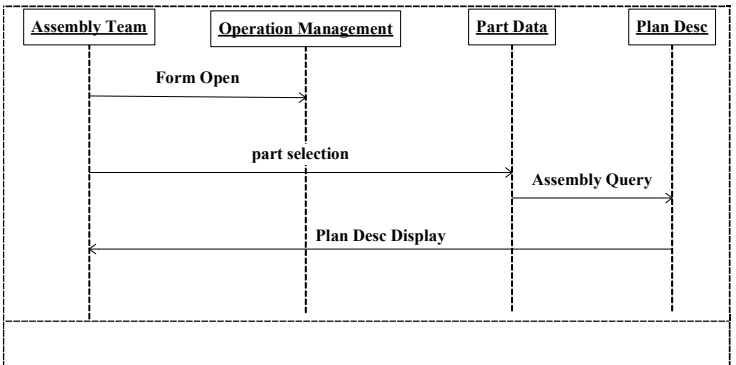

Fig. 2. Sequence diagram of integrated CAPP-BOM

An activity diagram is one of unified modelling language notation that reflect the program flow within the individual methods, regardless of simple or object-oriented declaration. The activity diagram of integrated CAPP-BOM shows in figure 3 below.

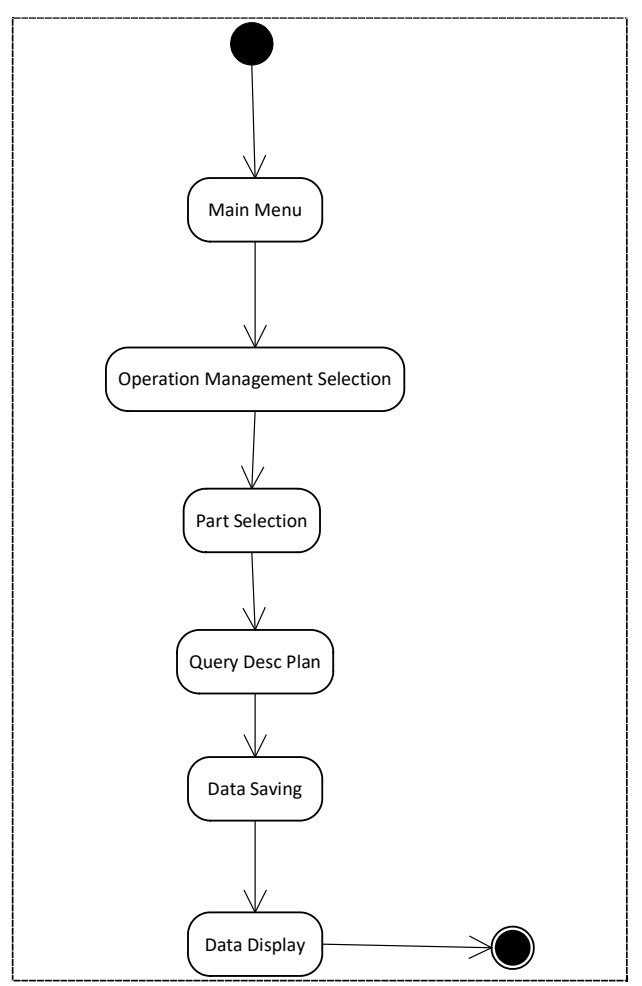

Fig. 3. Activity diagram of integrated CAPP-BOM

\section{Conclusion}

Industry 4.0 has changed manufacturing activities become more computerized. In the industry 4.0 environment, the needed for automation and digitization is increasingly high. The intense competition in the manufacturing industry and the dynamic market of customer make the industry must to implement the industry 4.0 concept in their activity. CAPP as a process planning tools in the manufacturing is believed to be able to increase competitive advantages and responsive to the market. CAPP that is integrated with complete data or information can be used as a weapon that can strengthen CAPP ability to be more effective. By integrating CAPP with BOM, its expected to reduce the planning process time so that the result of CAPP become more effective and efficient.

Thanks to the Department of Informatics Engineering, Trunojoyo University, Indonesia for their extraordinary courage and for supporting this paper.

\section{References}

[1] H.C. Zhang, L. Alting, "computerized manufacturing process planning system", Chapman and Hall, (1994).

[2] Ahmad, Nafis, Anwarul Haque AFM, Hasin AA. Current trends in computer aided process planning. Proceedings of the seventh annual paper meet and 2nd international conference, The Institution of Engineers, Bangladesh, Mechanical Engineering Division 25-27. Paper No. 10; (2001). p. 81-92.

[3] DRM Associates. CAPP, [Online] 2003 [cited (2019), Apr.10]; accessed on: URL: /http://www.npd-solutions.com/index.htmlS.

[4] Groover, Michael. Fundamentals of modern manufacturing. Englewood Cliffs, NJ: PrenticeHall; (1997).

[5] ElMaraghy, H., Schuh, G., ElMaraghy, W., Piller, F., Scho“ nsleben, P., Tseng, M., Bernard, A., (2013), Product Variety Management, CIRP Annals-Manufacturing Technology, 62/2: 629652.

[6] Orlicky, J.A., (1971), Material Requirements Planning, McGraw-Hill, New York, NY.

[7] Orlicky, J.A., Plossl, G.W., Wight, O.W., (1972), Structuring the Bill of Material for MRP, Production and Inventory Management, 13:1942.

[8] Kashkoush Mohammed and ElMaraghy Hoda, (2015), Product family formation by matching bill-of-materials trees, CIRP Journal of manufacturing science and technology.

[9] L. Heuser, Z. Nochta, N.C. Trunk, ICT shaping the world: A scientific view. ETSI, Wiley Publication, London, (2008).

[10] Lee, J., Lapira, E., Bagheri, B., Kao, H., (2013). Recent advances and trends in predictive manufacturing systems in big data environment. Manuf. Lett. 1 (1), 38-41. 